\title{
EFFECT OF METHIONINE AND METHIONINE SULPHOXIMINE ON RAT BRAIN S-ADENOSYL METHIONINE LEVELS
}

\author{
R. A. SCHATZ and O. Z. Sellinger \\ Laboratory of Neurochemistry, Mental Health Research Institute, University of Michigan Medical Center, \\ Ann Arbor, MI 48104, U.S.A.
}

(Accepted 24 August 1974)

\begin{abstract}
Rat brain SAM levels were markedly increased after methionine administration, whereas the convulsant, L-methionine-dl-sulphoximine (MSO), produced a 35 per cent decrease in whole brain content of $S$-adenosyl-L-methionine (SAM). When methionine was given in combination with MSO, SAM levels were not decreased. Studies on the regional distribution of SAM revealed only a small variation between regions (from $24 \mathrm{nmol} / \mathrm{g}$ in midbrain to $49.5 \mathrm{nmol} / \mathrm{g}$ in striatum). SAM levels were reduced by about 50 per cent in the cerebellum, striatum, cortex and hippocampus 3 and $6 \mathrm{~h}$ after MSO. It is proposed that abberant cerebral methylation processes may be involved in the genesis of the MSO seizure.
\end{abstract}

THE USE of the convulsant, methionine sulphoximine (MSO), to study seizure mechanisms is advantageous in that its rather long preconvulsive latency period (36 h) (Reiner et al., 1950) allows one to follow the course of specific cellular and metabolic alterations resulting from its administration. Previous studies (Lodin \& Kolousek, 1958; Lamar \& Sellinger, 1965; SELLINGER et al., 1970) have demonstrated that L-methionine administered concurrently with MSO in a 5:1 molar ratio markedly reduces the incidence and severity of seizures.

The importance of S-adenosyl methionine (SAM) as a methyl donor (LOMBARDINI \& TALALAY, 1971), the structural similarities between MSO, methionine and SAM and the fact that both BALDESSARINI (1966) and SALVATORE et al. (1971) reported that methionine administration increased SAM levels in rat and rabbit brain, respectively, led us to investigate the effect of MSO and methionine on SAM levels in rat whole brain and brain regions.

\section{MATERIALS AND METHODS}

\section{Materials}

L-Methionine-dl-sulphoximine (MSO) was obtained from Sigma Chemical Co. (St. Louis, Missouri); L-methionine, from ICN Nutritional Biochemicals (Cleveland, Ohio) and $S$-adenosyl-L-methionine, from P-L Biochemicals Inc. (Milwaukee, Wisconsin). Radioactive $S$-adenosyl-L-methionine [methyl ${ }^{14} \mathrm{C}$ ] (SAM) (specific activity $52 \mathrm{mCl} / \mathrm{mmol}$ ) and

Abbreviations used: MSO, L-methionine-dl-sulphoximine; SAM, S-adenosyl-L-methionine. $\left[{ }^{14} \mathrm{C}\right]$ toluene $\left(4.26 \times 10^{5} \mathrm{~d}\right.$.p.m. $\left./ \mathrm{ml}\right)$ were purchased from New England Nuclear (Boston, MA). PCS (a tissue solubilizer-scintillant mixture) was obtained from Amersham Searle (Arlington Heights, IL). Silica gel TLC plates F-254 (with fluorescent indicator) were from EM Laboratories (Elmsford, NY). Dowex 50W-X8 resin was from Baker Chemical Co. (Phillipsburg, NJ) and was converted to the $\mathrm{Na}^{+}$form prior to use (Shapiro \& Ehninger, 1966).

\section{Injection and sacrifice}

Male Sprague-Dawley rats $(100-200 \mathrm{~g})$ were injected intraperitoneally with saline $(10 \mathrm{ml} / \mathrm{kg})$, methionine $(4 \cdot 7$ $\mathrm{mmol} / \mathrm{kg})$, MSO $(0.94 \mathrm{mmol} / \mathrm{kg})$, or both MSO and methionine 1,3 and $6 \mathrm{~h}$ prior to sacrifice. Sacrifice was always between the hours of 11 a.m. and 2 p.m. After sacrifice by decapitation, whole brains were rapidly removed, frozen in liquid nitrogen and stored at $-65^{\circ} \mathrm{C}$. For regional analyses, brains were rapidly dissected on ice (GLOWINSKI \& IVERSEN, 1966), regions pooled in groups of three and immediately frozen and stored as above. Samples remained stored no longer than $21 \mathrm{~h}$ before being analysed for SAM content.

\section{Analytical}

$S$-adenosyl methionine was measured by the radioisotope dilution technique of SALVATORE et al. (1971). Brains or regions were homogenized in $1.5 \mathrm{M}$-perchloric acid containing from 0.08 to $0.2 \mu \mathrm{mol}$ SAM adjusted to a specific activity of $0.5 \times 10^{5}-2 \times 10^{5}$ c.p.m. $/ \mu \mathrm{mol}$ by the addition of nonradioactive SAM purified according to SHAPIRO \& EHNINGER (1966). After centrifugation at $9000 \mathrm{~g}$ for $15 \mathrm{~min}$, the supernatants were adjusted to $\mathrm{pH} 6$ by very slow dropwise addition of $1.0 \mathrm{~N} \mathrm{KOH}$ in the cold with constant stirring. After $\mathrm{pH}$ adjustment, samples were centrifuged for 15 $\min$ at $9000 \mathrm{~g}$ and the supernatants added to Dowex 50 $\left(\mathrm{Na}^{+}\right)$columns $(3 \times 0.4 \mathrm{~cm})$. The columns were thistle top 
funnel tubes $(30 \times 0.4 \mathrm{~cm})$ to which were attached $2 \mathrm{~cm}$ lengths of tygon tubing and open jaw screw clamps. Eluting agents were $0.1 \mathrm{M} \mathrm{NaCl}$ followed by $6 \mathrm{~N} \mathrm{HCl}$ and elution was continued until the absorbance of the acid eluate was less than $0-01$ at $256 \mathrm{~nm}$. One $\mathrm{ml}$ of acid eluate was combined with $10 \mathrm{ml} \mathrm{PCS}$ and counted in a Nuclear Chicago Unilux II liquid scintillation counter. Absorbances of the acid eluates were measured in a Beckman Acta II spectrophotometer at $256 \mathrm{~nm}$ and SAM concentration calculated using the molar extinction coefficient of 14,700 (SHAPIRO \& EHNINGER, 1966). Two standards were carried through the experimental procedure each day. Acid eluates were intermittently checked for purity of SAM on silica gel F-254 TLC plates by isographic migration with authentic SAM. Solvent systems used were $n$-butanol-acetic acid-water (60:15:25), ethanol-acetic acid-water (64-1-35) (SALVATORE et al., 1971) and $20 \% \mathrm{KCl}-5 \%$ acetone-water (COHN et al., 1972). Ninhydrin spray $(0.25 \%, w / v$, in acetone) for amino acids, the u.v. quenching reaction for purine compounds (SALVATORE et al., 1971), the chloroplatinate spray for sulfur compounds (WONG, 1971) and autoradiography were used for identification of SAM.

Reproducibility of the SAM assay was markedly decreased when tissue weights of less than $150 \mathrm{mg}$ were assayed. Indeed, there was a significant correlation between tissue weight and standard error $(r=0.64, P<0.05)$.

\section{RESULTS}

Table 1 represents the regional distribution of SAM in rat brain. The range of variation in SAM levels between brain regions is rather small with the highest level in the striatum $(49.5 \mathrm{nmol} / \mathrm{g})$ and the lowest in the midbrain $(24 \mathrm{nmol} / \mathrm{g})$.

Administration of MSO resulted in a gradual decrease of whole brain SAM levels reaching a maximum at $6 \mathrm{~h}(-47 \%)$ (Fig. 1). Methionine, on the other hand, produced a marked increase in SAM that reached a

Table 1. Regional distribution of S-ADEnOsyl-methIONINE IN RAT BRAIN

\begin{tabular}{lc}
\hline Brain region & S-Adenosyl-methionine \\
\hline Cerebellum & $44 \cdot 6 \pm 4 \cdot 16(16)$ \\
Brainstem & $29 \cdot 6 \pm 2 \cdot 08(17)$ \\
Striatum & $49 \cdot 5 \pm 4 \cdot 77(17)$ \\
Hypothalamus & $26 \cdot 0 \pm 4 \cdot 41(11)$ \\
Midbrain & $24 \cdot 0 \pm 2 \cdot 20(17)$ \\
Hippocampus & $32 \cdot 9 \pm 3 \cdot 60(17)$ \\
Cerebral cortex & $30 \cdot 5 \pm 1 \cdot 98(17)$ \\
Whole brain & $31 \cdot 1 \pm 2 \cdot 15(15)$ \\
\hline
\end{tabular}

Values are expressed as $\mathrm{nmol} / \mathrm{g}$ brain and are means \pm S.E.M.

Numbers in parentheses represent numbers of determinations.

Brain regions from three rats were pooled for each determination.

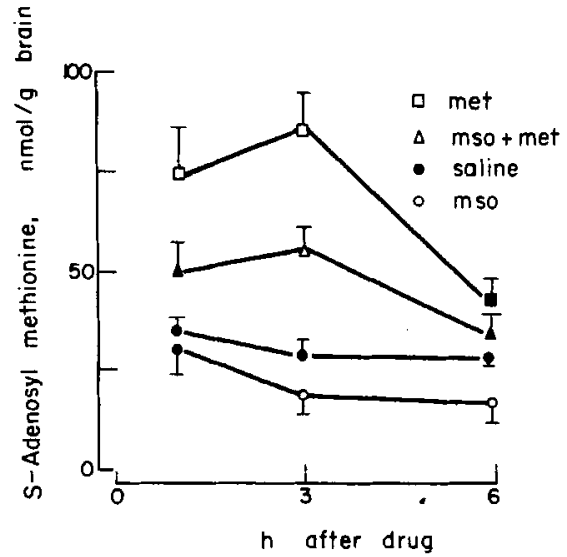

FIG. 1. Effect of methionine or methionine sulphoximine on rat brain $S$-adenosyl-methionine levels. L-Methionine $(4.7 \mathrm{mmol} / \mathrm{kg})$ or L-methionine sulphoximine $(0.94 \mathrm{mmol} /$ $\mathrm{kg}$ ) were administered intraperitoneally. Each value represents the mean \pm S.E.M. of 5-6 rats. Open symbols denote a significant difference from corresponding saline values at the 0.05 level using the Student $t$-test.

value about 200 per cent that of saline controls at $3 \mathrm{~h}$, but was not significantly increased $(+29$ per cent $)$ at $6 \mathrm{~h}$. Animals receiving a combination of MSO and methionine showed no significant differences in SAM levels at 1 and $6 \mathrm{~h}$ but at $3 \mathrm{~h}$ SAM levels were significantly elevated (Fig. 1).

One hour after MSO, SAM was decreased by about

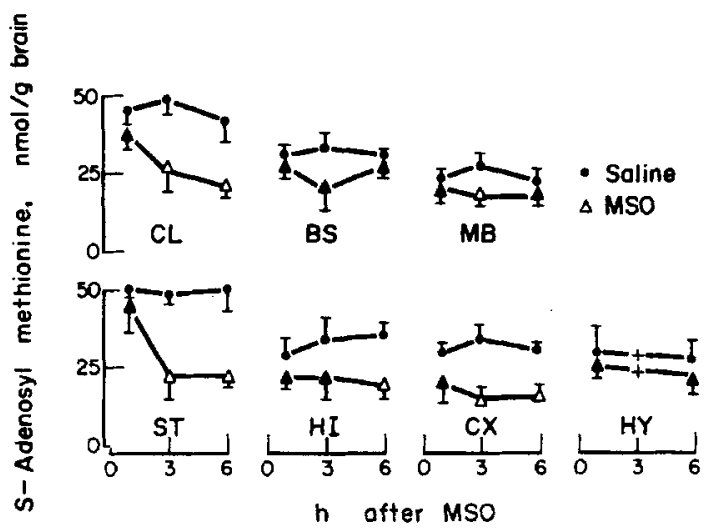

FIG. 2. Effect of methionine sulphoximine on $S$-adenosyl methionine levels in rat brain regions. $\mathrm{CL}$-cerebellum, BS-brainstem, MB-midbrain, ST--striatum, HI-hippocampus, CX - cortex, HY - hypothalamus. Each value represents the mean of 5-6 determinations \pm S.E.M. Regions from the brains of three rats were pooled for each determination. Open symbols denote a significant difference from corresponding saline value at the 0.05 level using the Student $t$ test. $(+)$ Values not available 
25 per cent in the hippocampus and cortex and by 14 per cent in the cerebellum, whereas other regions showed no significant changes in SAM content (Fig. 2). Three and six hours after MSO, SAM was about 50 per cent of control values in the cerebellum, striatum, hippocampus and cortex. At these time periods SAM levels in the brainstem, midbrain and hypothalamus were slightly decreased, the only significant reduction being in the midbrain at $3 \mathrm{~h}$ (Fig. 2).

\section{DISCUSSION}

There were no striking differences in the regional distribution of SAM in rat brain (Table 1). These data are generally in agreement with previous findings (BALDESSARINI \& KOPIN, 1966), the only exception being the high cerebellar SAM values in the present study. As yet, this result remains unexplained but TLC chromatography of the cerebellar eluates revealed no detectable spots other than SAM (see Methods).

Methionine has been shown to elevate rat (BALDESSARINI, 1966) and rabbit brain SAM levels (SALVATORE et al., 1971). Such a result has been demonstrated in this study (Fig. 1). Further, the decrease in SAM levels after $\mathrm{MSO}$ is prevented by the concomitant administration of methionine. The reason for this is thought to be that methionine competitively decreases the amount of MSO entering the brain (GHITTONI et al., 1970), a similar competitive transport relationship recently having been noted in unicellular algae (MEINS \& ABRAMS, 1972). Moreover, the ability of methionine to antagonize MSO seizures is markedly decreased if methionine is given $60 \mathrm{~min}$ or more after MSO (SELLINGER et al., 1968). Thus the concomitant administration of methionine and MSO probably does not allow sufficient MSO to enter the CNS either to produce seizures or to reduce SAM levels.

The marked increase in SAM levels after methionine (Fig. 1) is probably the result of increased precursor availability, especially since the conversion of methionine to SAM in rat brain occurs very rapidly in vivo (BALDESSARINI \& KoPIN, 1966).

Since SAM levels were depressed prior to MSO seizures, the possibility of a causal relationship between levels of SAM and the MSO seizure may be entertained. At present, however, this appears untenable since pargyline (BALDESSARINI, 1966) and DOPA (WUR TMAN et al., 1970) both decrease SAM but neither is known to produce convulsions. It is possible, however, that localized pools of SAM exist in cellular compartments (JuDES \& JACOB, 1972), and that DOPA and pargyline alter levels of SAM in a pool other than that affected by MSO.
The mechanism(s) whereby MSO lowers brain SAM levels may involve a decreased synthesis of SAM by the methionine activating enzyme (ATP: L-methionine adenosyl transferase; EC 2.4.2.13), an increased utilization of SAM by various cerebral methyl transferases or a combination of both of these processes. LOMBARDINI et al. (1970) have reported that MSO is neither a substrate nor an inhibitor of the rat liver methionine activating enzyme in vitro, and we have reported no inhibitory effects of MSO on this enzyme in rat cerebral cortex and cerebellum (SCHATZ et al., 1973).

DE ROBERTIS et al. (1967) have provided preliminary evidence for the alternate mechanism, that is, one operating to increase utilization of SAM by cerebral methyl transferases, for they noted a marked increase in rat brain catechol-O-methyltransferase activity $6 \mathrm{~h}$ after MSO administration.

The striking effect of MSO on cerebral SAM levels most probably reflects marked alterations of methylation processes in brain. Perhaps aberrant methylation of brain amines, or of certain key macromolecules, is at least in part responsible for the ability of MSO to elicit seizures.

Acknowledgement-Supported by grants MH 07417, NS 06294 and a grant from the Epilepsy Foundation of America.

\section{REFERENCES}

Baldessarini R. J. (1966) Biochem. Pharmac. 15, 741-748.

Baldessarini R. J. \& KoPIN I. J. (1966) J. Neurochem. 13, 769-777.

Cohn C. K., Vesell E. S. \& Axelrod J. (1972) Biochem. Pharmac. 21, 803-809.

De Robertis E., Sellinger O. Z., Rodriguez De Lores Arnaiz G., ALberici M. \& Zieher L. M. (1967) J. Neurochem. 14, 81-89.

Ghittoni N. E., Ohlsson W. G. \& Sellinger O. Z. (1970) J. Neurochem. 17, 1057-1068.

GLOWINSKI J. \& IVERSEN L. L. (1966) J. Neurochem. 13, 655669.

Lamar C. Jr. \& Sellinger O. Z. (1965) Biochem. Pharmac. 14, 489-506.

Lodin Z. \& Kolousek J. (1958) Physiol Bohemoslov. 7, 292 298.

Lombardini J. B., Coulter A. W. \& Talalay P. (1970) Molec. Pharmac. 6, 481-499.

Lombardini J. B. \& Talalay P. (1971) Advances in Enzyme Regulation 9, 349-384.

Meins F. Jr. \& Abrams M. L. (1972) Biochim. biophys. Acta 266, 307-311.

Reiner L., Misani F. \& Weiss P. (1950) Archs. Biochem. Biophys. 25, 447-454.

Salvatore F., Utili R., Zappia V. \& Shapiro S. K. (1971) Analyt. Biochem. 41, 16-28. 
Schatz R., Diez-Altares M. C. \& Sellinger O. Z. (1973) Shapiro S. K. \& Ehninger D. J. (1966) Analyt. Biochem. 15, Trans. Am. Soc. Neurochem. 4, 74.

Sellinger O. Z., Azcurra J. M. \& Ohlsson W. G. (1968)

J. Pharmac. exp. Ther. 164, 212-222. 323-333.

WONG F. F. (1971) J. Chromatogr. 59, 448-457.

Wurtman R. J., Rose C. M., Matthysse S., Stephenson J. \& Baldessarini R. J. (1970) Science, N.Y. 169, 395-397. 